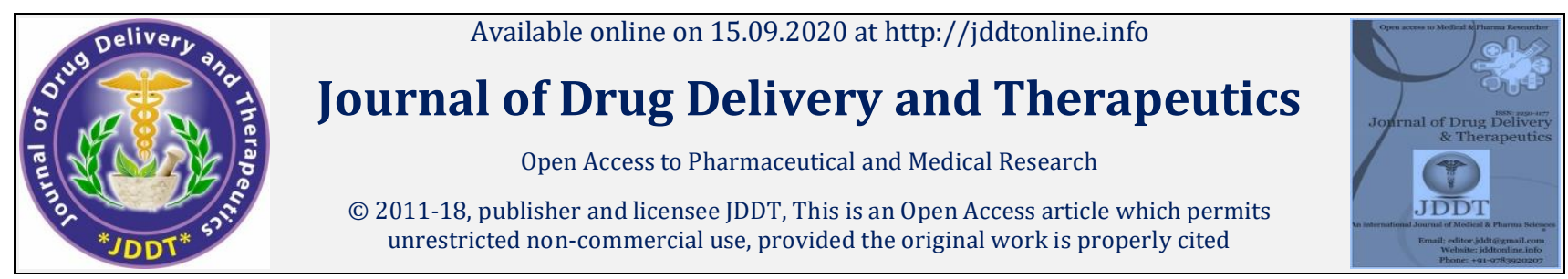

Open $\odot$ Access

Research Article

\title{
Antioxidant Activity and Phytochemical Analysis of Leaf Extracts of Pineapple
}

\author{
${ }^{1}$ Diksha Sahu*, ${ }^{1}$ Bhavana Yadav, ${ }^{1}$ Shivanki Verma, ${ }^{1}$ Abhay Pratap Yadav, ${ }^{2}$ Vijay Kumar Tilak, ${ }^{3}$ Sheo Datta Maurya \\ ${ }^{1}$ R.K. Pharmacy College, Azamgarh, Uttar Pradesh-276406, India \\ ${ }^{2}$ Apex Professional University, Pasighat, Arunachal Pradesh-791102, India \\ ${ }^{3}$ Sarvodaya College of Pharmacy, Azamgarh, Uttar Pradesh-276001, India
}

\begin{abstract}
Traditional medicines are originated from plants that do not form the constituent of routein diet. Beside this most of the me dicinal plants have not received much attention / screening. Ananas comosus is one such plant traditionally used for treatment of various ailments. The pineapple (A. comosus) is the edible member of family Bromeliaceae; Phytochemical screening of the A. Comosus leaves extract shows presence of Alkaloids, Flavonoids, Tannins, Phytosterols, Glycosides and Phenols. The present study was designed to evaluate the effect of crude extract of pineapple leaves (PAL) for antioxidant activity. The value of inhibition of 3 extracts of A. comosus on 2, 2 Diphenyl-1 picrylhydrazyl (DPPH) assays at a concentration of $99 \mu \mathrm{g} / \mathrm{mL}$ was obtained. Result shows highest inhibition which is obtained by hydro alcoholic solution (56.40) and lowest by ethanolic extract (42.86) respectively. Ascorbic acid as positive control shows $96.5 \%$ antioxidant activity.
\end{abstract}

Keywords: Bromeliaceae, Flavonoids, Memory enhancement, Antioxidant, DPPH.

Article Info: Received 14 July 2020; Review Completed 23 Aug 2020; Accepted 30 August 2020; Available online 15 September 2020

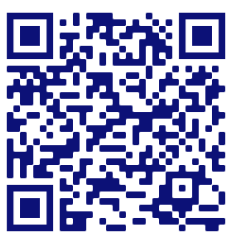

Cite this article as:

Sahu D, Yadav B, Verma S, Yadav AP, Tilak VK, Maurya SD, Antioxidant Activity and Phytochemical Analysis of Leaf Extracts of Pineapple, Journal of Drug Delivery and Therapeutics. 2020; 10(5):165-167

http://dx.doi.org/10.22270/jddt.v10i5.4397

Diksha Sahu, R.K. Pharmacy College, Azamgarh, Uttar Pradesh-276403, India

\section{INTRODUCTION:}

The pineapple (Ananas Comosus Linn.) is the leading edible member of the family Bromeliaceae which embraces about 2,000 species, mostly epiphytic and many strikingly ornamental. The pineapple plant is a terrestrial herb $21 / 2$ to $5 \mathrm{ft}$. high with a spread of 3 to $4 \mathrm{ft}$.; a very short, stout stem and a rosette of waxy, strap like leaves, long-pointed, 20 to 72 inch long; usually needle tipped and generally bearing sharp, up curved spines on the margins. The leaves may be all green or variously striped with red, yellow or ivory down the middle or near the margins. ${ }^{1}$

As individual fruits develop from the flowers they join together forming a cone shaped, compound, juicy, fleshy fruit to 12 inch or more in height, with the stem serving as the fibrous but fairly succulent core. The tough, waxy rind, made up of hexagonal units, may be dark-green, yellow, orangeyellow or reddish when the fruit is ripe. The flesh ranges from nearly white to yellow. ${ }^{2}$

It is commonly found in Asia, Africa, India and other tropical \& subtropical regions. Primarily this plant is used as an intoxicant and amnesia. ${ }^{3}$ The leaves and fruit of pineapple species were rich in alkaloids, including atropine, scopolamine and hyoscyamine.4-6 The phytoconstituents such as flavonoids, phenols, tannins, glycosides and sterols are found in . comosus. $^{7}$

It is widely use in India, for the treatment of epilepsy, dementia, heart diseases, cough, \& inflammation etc ${ }^{8-9} A$. comosus was also been used for its anaesthetic orpain- killing properties. Several scientific studies have been reported on antioxidant and phytochemical screening of ethanol and hydro-alcoholic crude extract. ${ }^{10-12}$

\section{MATERIALS AND METHODS: \\ Collection of leaves:}

The leaves were collected from the field of local area and authenticated by Prof. Nawal Kishore Dubey, Centre of Advanced Study in Botany, Institute of Science, Banaras Hindu University, Varanasi, 221005. The collected leaves were washed with water to remove dust and then washed leaves were shade dried for 40 days. After drying the leaves were ground into powder form using a mixer. 


\section{Extract preparation: 12}

Soxhlet Extractor: 25 grams of coarse powder of $A$. comosus leaf was packed in a muslin cloth bag and placed in the body of Soxhlet extractor. Then, $500 \mathrm{~mL}$ of Solvent (Ethanol, Methanol, Hydroalcoholic Solution) was poured in the round-bottom flask. The apparatus was then fitted with the help of clamps and stand to support the Soxhlet extractor, round-bottom flask, and condenser. The rubber tube connected to the tap water was attached to the condenser for continuous flow of water. The solvent was heated using the isomantle, which began to evaporate, moving through the apparatus to the condenser. The condensate then dripped into the reservoir containing the plant extract. Once the level of solvent reached the siphon, it poured back into the flask and the cycle began again. The process was made to run for a total of $6 \mathrm{~h}$. Finally, the extract (PAL) was collected in the round-bottom flask. Once the process was finished, the ethanol was evaporated using rotary evaporator at $40^{\circ} \mathrm{C}$, leaving a small yield of extracted plant material (about 2-3 $\mathrm{mL}$ ) in the glass-bottom flask. Extract was kept in a porcelain bowl till the remaining ethanol was completely evaporated. The content of extractable matter was calculated in $\mathrm{mg} / \mathrm{g}$ of air-dried material using digital weighing balance. The extract was stored in the refrigerator till further use.
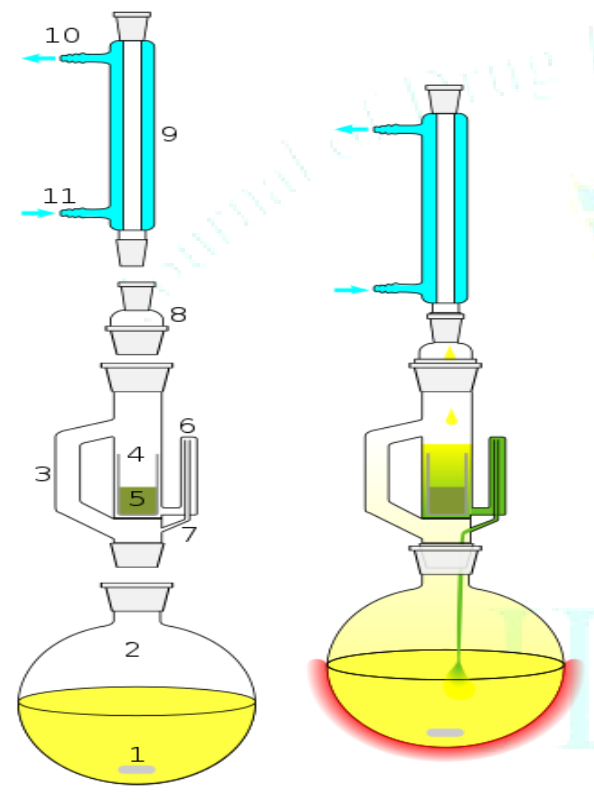

Figure 1: Soxhlet Apparatus

\section{Phytochemical screening:}

The phytochemical tests were done for analysing different chemical groups present in the PAL 13,16

Test for alkaloids: Took $3 \mathrm{~mL}$ of PAL with few drops of $1 \%$ $\mathrm{HCl}$ and heated on steam bath followed by addition of few drops of Mayer \&Wagner's reagent. Turbidity indicates the presence of alkaloids.

Test for flavonoids: To $1 \mathrm{~mL}$ of PAL added $1 \mathrm{~mL}$ of $10 \%$ Lead acetate solution. Yellow precipitate formed, indicates presence of flavonoids.

Test for saponin: $2 \mathrm{~mL}$ of PAL was shaken vigorously with 5 $\mathrm{mL}$ of distilled water and heated on water bath; stable foam was formed, indicates the presence of saponin.

Test for tannins: $2 \mathrm{~mL}$ of PAL was taken with $2 \mathrm{~mL}$ of distilled water and stirred followed by addition of few drops of Ferric chloride solution, green precipitate appeared, showed presence of tannins.

Test for steroids: Dissolved $2 \mathrm{~mL}$ of PAL into Chloroform and added $2 \mathrm{~mL}$ of concentrated Sulphuric acid to the mixture, red colour developed indicates presence of steroids.

Test for terpenoids: Take $1 \mathrm{~mL}$ of PAL followed by addition of $0.5 \mathrm{~mL}$ of acetic anhydride and then few drops of concentrated Sulphuric acid. Appearance of Bluish green precipitate confirmed presence of terpenoids.

Test for phlobatannins: $2 \mathrm{~mL}$ of PAL was hydrolysed using $1 \% \mathrm{HCl}$ and mixture was boiled for few minutes. Deposition of red precipitate indicates the presence of phlobatannins.

Test for glycosides: Dissolved $2 \mathrm{~mL}$ of PAL into Chloroform and add $2 \mathrm{~mL}$ of Acetic acid into the mixture followed by heating than cooled. Added few drops of Sulphuric acid colour changed from blue to green confirmed presence of glycosides.

Test for amino acids:Took $1 \mathrm{~mL}$ of PAL and treated with few drops of Ninhydrin reagent, development of purple colour confirmed presence of amino acids.

\section{Antioxidant activity:}

DPPH free radical scavenging: The DPPH assay was done according to the method reported by Brand -Williams Method $^{17}$ using Ascorbic acid as standard. Samples were prepared using PAL $(10 \mathrm{mg} / \mathrm{mL})$. The sample solutions $(33 \mu \mathrm{L})$ were added with $1 \mathrm{~mL}$ DPPH solution. The mixture was vortexed vigorously for 1 minute and kept in a dark for 20 minutes at $27^{\circ} \mathrm{C}$, absorbance of all samples were taken at $517 \mathrm{~nm}$. The percentage inhibition was calculated using the formula,

$\%$ Inhibition $=$ Abs control - Abs extract $/$ Abs control $\times 100$.

\section{RESULT AND DISCUSSION:}

\section{Ananas Comosus Leaf Extract (PAL):}

Various extract were obtained using Methanol, Ethanol and Hydro-alcoholic Solution. The percentage yields are presented in table 1.

Table 1: Extraction yield of PAL

\begin{tabular}{|l|c|c|}
\hline Solvent & Extraction Yield (g) & Yield (\%) \\
\hline Methanol & 7.04 & 7.04 \\
\hline Ethanol & 7.36 & 7.36 \\
\hline $\begin{array}{l}\text { Hydro-alcoholic } \\
\text { Solution }\end{array}$ & 4.48 & 4.48 \\
\hline
\end{tabular}

Highest \% Yield was obtained in ethanol followed by methanol and hydro alcoholic solution because ethanol can extract polar as well as non-polar components.

\section{Phytochemical screening:}

Phytochemical screening shows presence of flavonoids, tannins, alkaloids and glycosides. Different phytochemical constituents which are present in samples are known to be biologically active compounds and they are responsible for different activities such as antimicrobial, antioxidant, antifungal, anticancer and antidiabetic activities. Tannins, glycosides, flavonoids, and glycosides have hypoglycaemic and anti-inflammatory activities. ${ }^{13,} 15$ 
Table 2: Phytochemical analysis of PAL

\begin{tabular}{|c|c|}
\hline Component & Result \\
\hline Alkaloid & ++ \\
\hline Tannins & ++ \\
\hline Saponins & - \\
\hline Flavonoids & - \\
\hline Steroids & - \\
\hline Terpenoids & ++ \\
\hline Glycosides & - \\
\hline Amino acid & \\
\hline \multicolumn{2}{|c|}{+ = Presence; - = Absence. }
\end{tabular}

Antioxidant activity:

DPPH radical scavenging: The photometric evaluation of the antioxidant activity of PAL shows good antioxidant capacity. The value of inhibition of 3 PALon DPPH assay at a concentration of $99 \mu \mathrm{g} / \mathrm{mL}$ was obtained. Result shows highest inhibition which is obtained by hydro alcoholic solution (56.40) and lowest by ethanolic extract (42.86) respectively. Ascorbic acid as positive control shows $96.5 \%$ antioxidant activity. Results show that the polar extracts have highest antioxidant activity.

Table 3: DPPH free radical scavenging activity of PLE

\begin{tabular}{|l|c|}
\hline Solvent & \% Inhibition \\
\hline Ascorbic Acid & 96.52 \\
\hline Methanol & 47.52 \\
\hline Ethanol & 42.86 \\
\hline Hydro-alcoholic Solution & 56.40 \\
\hline
\end{tabular}

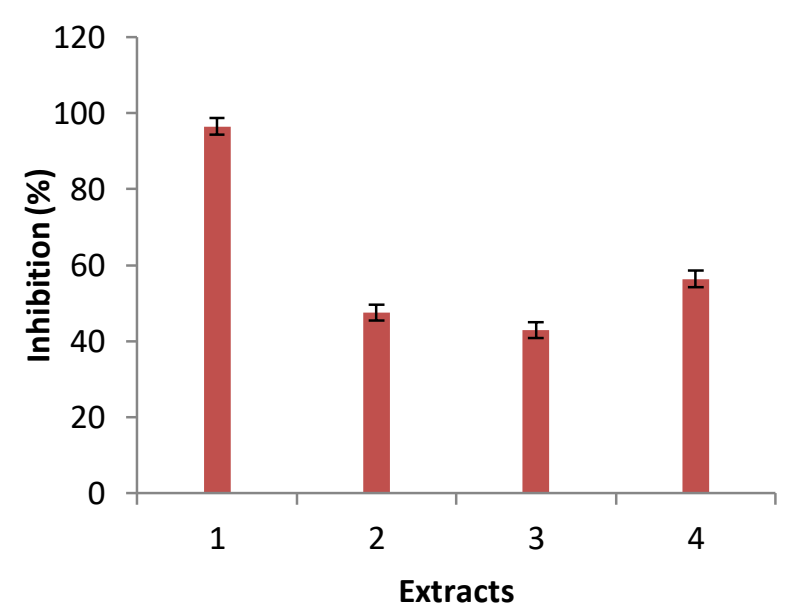

Figure2: DPPH free radical scavenging activity of PAL such as Ascorbic Acid (1), Methanol (2), Ethanol (3) and Hydroalcoholic Solution. Each bar shows mean \pm SD $(n=3)$

\section{CONCLUSION:}

High antioxidant activity was observed in hydro-alcoholic extractsof $A$. comosus. When compared to other extracts. The PAL shows the presence of secondary metabolites such as Alkaloids, Glycosides, Phlobatannins, Tannins and Flavonoids. The bioactive compounds from A. comosus serve as good phototherapeutic agent. The value of inhibition of 3 PAL on DPPH assay at a concentration of $99 \mu \mathrm{g} / \mathrm{mL}$ was obtained. Result shows highest inhibition which is obtained by hydro alcoholic solution (56.40) and lowest by ethanolic extract (42.86) respectively. Present study shows that pineapple leaf extract can be used as antioxidant as well as memory enhancer.

Acknowledgement: The authors are thankful to the R.K Pharmacy College, Azamgarh, Uttar Pradesh, for providing the necessary facilities to carry out the research work.

\section{REFERENCES:}

1) Morton J, Julia FM, Miami FL. Pineapple: Fruits of warm climates. 1987; 18-28.

2) Kokate KK, Purohit AP, Gokhale SB, Pharmacognosy, Forty second edition, Vallabh Prakashan, India. 2008; 13-44.

3) Meda A, Lamien CE, Romito M, Millogo JNacoulma OG. Determination of the total phenolic, flavonoid and praline contents in Burkina Fasan honey as well as their radical scavenging activity. Food Chemistry. 2005; 91(3):571-577.

4) Yusuf.Phytochemical and antimicrobial studies. International Journal of Pharmacognosy.1991; 29:252-258.

5) Donatus EO, Ephraim CL. Isolation Characterization and antibacterial activity of alkaloid from Datura metel Linn leaves. African Journal of pharmacy and pharmacology. 2009; (5):277-281.

6) Chopra. RN, Nayar SL, Chopra IC, Glossary of Indian medicinal plants. Council of Scientific and Industrial Research, New Delhi, 1986.

7) Putri DA, Ulfi A, Purnomo AS, Fatmawati S. Antioxidant and antibacterial activities of Ananas Comosus Peel extracts. Malaysian Journal of Fundamental and Applies Sciences. 2018; 14(2):307-311.

8) Walter JP, Pasqualina P, Hannes BS. The Relation between Antioxidants and Memory Performance in the Old and Very Old. J Am Geriatric. 2014; 45:718-724, 1997.

9) Lufang Z, Guichen L, Dawei G, Shuo W, Xiangfei M, Cong W, Haibo Y, Li C. Cognitive frailty as a predictor of dementia among older adults: A systemati review and meta-analysis. Archives of Gerontology and Geriatrics. 2020; 87:103997.

10) Chao $M$, Sheng-yuan $X$, Zhen-guo L, Wei W, Li-jun D. Characterization of active phenolic components in the ethanolic extract of Ananas comosus L. leaves using highperformance liquid chromatography with diode array detection and tandem mass spectrometry. Journal of Chromatography A, 2007; 1165:39-44.

11) Oluwaseun PB, Mofoluwaso BF. Chemical and antioxidant properties of snake tomato (Trichosanthes cucumerina) juice and Pineapple (Ananas comosus) juice blends and their changes during storage. Food Chemistry. 2017; 220:184-189.

12) Roopali M, Sankeshwari, Anil VA, Kishore B, Kirankumar H Soxhlet versus Cold Maceration: Which Method Gives Better Antimicrobial Activity to Licorice Extract against Streptococcus mutans. Journal of the Scientific Society. 2018; 45(2):67-71.

13) Saxena P, Panjwani D. Cardioprotective potential of hydroalcoholic fruit extract of Ananas comosus against isoproterenol induced myocardial infraction in Wistar Albino rats. Journal of Acute Disease. 2014; 228-234.

14) Rahman G, Syed UJ, Syed F, Samiullah S, Nusrat J. Preliminary Phytochemical Screening, Quantitative Analysis of Alkaloids, and Antioxidant Activity of Crude Plant Extracts from Ephedra intermedia Indigenous to Balochistan. The Scientific World Journal. 2017, Article ID 5873648, 7 pages.

15) H. Gerhard Vogel, Drug Discovery and Evaluation Pharmacological Assays. 2nd Edition. Page No- 623.

16) Momtazi-Borojeni AA, Sadeghi-Aliabadi H, Rabbani M, Ghannadi A, Abdollahi E. Cognitive enhancing of pineapple extract and juice in scopolamine-induced amnesia in mice. Res Pharm Sci. 2017; (12(3)):257-264.

17) Brand-Williams $W$, Cuvelier ME, Berset C. Use of a free radical method to evaluate antioxidant activity. LebensmWiss. U Technol. 2017; 28:25-30. 